\title{
Ambivalência e teto de vidro nas universidades: uma abordagem a partir dos relatos biográficos das professoras
}

Jensy Campos Céspedes* \& Teresa Pessoa**

* Profesora e investigadora del Centro de Investigaciones en Educación de la Escuela de Ciencias de la Educación, UNED, Costa Rica; ycampos@uned.ac.cr

** Profesora de la Facultad de Psicología y Educación de la Universidad de Coímbra, Portugal;

tpessoa@fpce.uc.pt

Recibido: 30 de agosto del 2018 Corregido: 25 de setiembre del 2018 Aceptado: 04 de octubre del 2018

\section{Resumo}

O artigo apresenta parte dos resultados de um projeto de pesquisa realizado em uma universidade costarriquenha sobre a condição das professoras universitárias. Como parte do estudo, foram elaboradas narrações biográficas de cinco docentes universitárias que atingiram o nível de catedráticas nas quais foram detectados, elementos comuns relacionados à ambivalência e as barreiras invisíveis que as professoras enfrentam na hora de ascender na carreira docente. A ambivalência é agudizada pelo casamento e a maternidade limitando o desenvolvimento acadêmico das professoras.

Palavras chave: Condição da mulher, direitos da mulher, discriminação, mulher docente, educação universitária, feminismo.

\section{Resumen}

\section{Ambivalencia y techo de cristal en las universidades: una aproximación desde los relatos biográficos de las profesoras}

El artículo presenta parte de los resultados de un proyecto de investigación realizado en una universidad costarricense sobre la condición de las profesoras universitarias. Como parte del estudio, se elaboraron narraciones biográficas de cinco docentes universitarias que alcanzaron nivel de catedráticas y se detectaron, dentro de estos relatos, elementos comunes que se relacionan con la ambivalencia y las barreras invisibles con las que se enfrentan las profesoras a la hora de ascender en carrera docente. La ambivalencia se agudiza con el matrimonio y la maternidad limitando el desarrollo académico de las profesoras.

Palabras clave: Condición de la mujer, derechos de la mujer, discriminación, docente mujer, Educación universitaria, feminismo.

\section{Abstract \\ Ambivalence and cristal roofs at the University: a biographical approach based on female professors accounts}

The article presents part of the results of a research project carried out at a University in Costa Rica on the condition of female professors at a university level. As part of the study, biographical narratives were elaborated by five female professors who reached the highest positions as professors in which were detected, common elements related to the ambivalence and the invisible barriers that the 
teachers face when ascending in their teaching career. This ambivalence is heightened by marriage and motherhood limiting the academic development of female teachers.

Key words: The female condition, women's rights, discrimination, female professors, higher education, feminism.

\section{INTRODUÇÃO}

Existe um número relevante de pesquisas centradas na vida das professoras nas quais são evidenciadas as desigualdades que, por razões de gênero, são experimentadas na cotidianidade nos contextos universitários. Essas pesquisas sublinham quais sãos as maiores dificuldades que as professoras têm para alcançar posições nas instâncias onde se dão as tomadas de decisões e a gestão com respeito as que têm os colegas do sexo masculino (Vicente, 2003; Tomàs, Duran, Guillamón \& Lavié, 2008; Castro \& Paredes, 2014; De Garay \& Valle-Díaz-Muñoz, 2012). Do mesmo jeito, existem estudos que evidenciam que o desenvolvimento acadêmico para as professoras universitárias é uma labor ainda mais difícil devido as tarefas asignadas socialmente pela sua condição de serem mulheres (Palomar, 2009; Tomàs, lon \& Bernabeu, 2013; Buquet, 2014; Flores, Soto \& Espejel, 2013). Dentro das dificuldades mais relevantes que a professoras enfrentam se encontram a ambivalência e o teto de cristal.

\section{Ambivalência}

A ambivalência entende-se como a situação na qual uma pessoa está impossibilitada de eleger entre duas posturas ou condutas incompatíveis e, por isso deve mantê-las e combiná-las. No estúdio realizado, a ambivalência, acontece pelas demandas que a estrutura familiar apresenta à mulher, isso combinado com as exigências que a mesma deve cumprir na universidade (Martínez 2012).

As professora universitárias vêm-se com uma sobre-exigência enquanto continuam assumindo a responsabilidade de atender à família, e ao mesmo tempo, enfrentando o desafio de realizar uma carreira acadêmica. $\mathrm{O}$ fato de se desenvolver como pessoa acadêmica na universidade implicas, para uma muIher, uma forte demanda em termos de preparação e dedicação ao estudo para atingir uma trajetória respeitável em um ambiente hostil e altamente competitivo.

Uma mulher que deseje desempenhar-se no âmbito universitário da mesma maneira em que o faria um homem, teria que "abandonar" em certa medida as responsabilidades domésticas e resistir à forte crítica que isto gera em nível familiar bem como na sociedade em geral. É por isso que na maioria dos casos as mulheres têm a tendência de adiar seu desenvolvimento acadêmico focando as suas energias na tarefa de cuidar das suas famílias (crianças e esposo), situação que é também recriminada por parte dos colegas acadêmicos e pela comunidade universitária.

A ambivalência nos espaços masculinizados é naturalizada ou bem negada. A esse respeito, Varcárcel (2012) aponta que as mulheres que chegam nesse espaços de poder masculino adotam "o traje valorativo adequado", onde a expressão: "eu nunca me senti discriminada" é uma das peças chave. Porém, "a pessoa que profere essas palavras nunca atingiu os umbrais perceptivos discriminatórios ou simplesmente mente" (p. 195).

Embora seja verdade o fato de que em algumas instituições a educação superior, a população docente é maioritariamente feminina, a estrutura cultural é de vocação masculina. Os códigos para o ascenso na carreira docente e no regime acadêmico, bem como às posições de mando, reclamam rituais 
masculinizados (Flecha, 2003). Apesar de que as condições tenham sido descritas amplamente pelos diferentes estúdios, as mulheres acadêmicas com frequência mostram resistência a relacionar estes eventos com os problemas de gênero no poder dentro do contexto acadêmico (Lozano, Iglesias \& Martínez, 2014).

A ambivalência é uma das situações que marca mais profundamente a condição da mulher nas novas sociedades e que termina sendo, por si mesma, uma forma de opresão pelos efeitos que produz em nível psicológico e emocional, mas também, em termos práticos no relacionado ao desempenho e à liberdade da mulher. Identicamente, o sistema meritocrático que supõe a regra universitária não considera essas condições de ambivalência, senão que as acentua posto que estabelece exigências maiores para ascender. Tanto a ambivalência como a meritocracia constituem condições de adversidade para as mulheres universitárias (Silva, Rodríguez \& Flores, 2009; Tomàs, Durán, Guillamón \& Lavié, 2008).

\section{Teto de cristal}

O teto de cristal refere à "uma série de mecanismos e sistemas de seleção e cooptação que davam como resulta que uma formação homóloga, as mulheres nunca obtiveram as metas que se corresponderiam com suas disposições" (Varcárcel, 2012, p. 137). De acordo com Vicente (2003), "o teto de cristal refere-se aos topos invisíveis e eficazes, barreiras que agem em um plano simbólico e que dificultam e limitam o progreso das mulheres dentro do nosso mundo acadêmico" (p. 175). É um elemento com o qual as acadêmicas devem lidar durante a sua trajetória de vida universitária (De Garay \& Del Valle-Díaz-Muñoz, 2012; Buquet, 2014), mas também as profissionais dentro de outros campos profissionais (Fuchs, Sauté, Oglensky \& Gever, 1995; Eagly \& Karau, 2002). A desigualdade de gênero e as barreiras para as mulheres são especialmente notáveis nas organizações no que concerne a posições de alta liderança (Clarke, 2011; Cook \& Glass, 2014; Hoyt, 2010; Jackson \& O'Callaghan, 2009).

As universidades não somente contam com o prestígio social e a missão socialmente conferida de criar conhecimento para propiciar transformações se não que também ostentam o privilégio da neutralidade que permite, que de uma ou outra maneira, fiquem blindados no que concerne ao tema de gênero (Tomàs, Durán, Guillamón y Lavié, 2008).

As estruturas universitárias masculinizadas, a sobre-exploração e a naturalização são condicões de adversidade que coloca sobre as docentes universitárias um "teto de cristal", que de maneira quase imperceptível limitam o desenvolvimento acadêmico e o ascenso às posições de mando na estrutura universitária (Vicente, 2003). Existem trabalhos de pesquisa que mostram a imperante liderança masculina na universidade e a ausência ou exclusão feminina como consequência de um conjunto de barreiras invisíveis (Moncayo \& Zuluaga, 2014).

A pesar dos avanços vindos do trabalho dos movimentos feministas, o fenômeno teto de cristal, continua sendo reproduzido em um conjunto de setores profissionais. Nesse sentido, segundo a autora, "a atual geração de mulheres em uma faixa etária dos trinta aos quarenta anos suporta, como nenhuma no passado, uma discriminação continua que além de tudo, tem pouco de sutil" (Varcárcel, 2012, p. 330).

\section{MATERIAIS E MÉTODOS}

Nesta pesquisa foi utilizado o método biográfico narrativo com cinco docentes com ampla experiência acadêmica (entre os 45 e os 65 anos de idade). Foi empregada a entrevista biográfica mediante a qual as participantes narraram suas trajetórias no desenvolvimento acadêmico como docentes no contexto 
universitário. Seguindo o proposto por Bolívar, Domínguez e Fernández (2001) a entrevista foi realizada em diferentes fases e implicou uma construção recorrente e um inter-análise.

\section{RESULTADOS}

\section{A ambivalência}

A ambivalência é uma constante na trajetória profissional das participantes. Ao longo do desenvolvimento acadêmico, as professoras, têm-se visto em um impasse não resolvido de eleger entre cuidar das tarefas acadêmicas (pesquisar, publicar, ou fazer uma pós-graduação) e satisfazer as demandas que o seu sistema familiar exige. A continuação mostra-se o fenômeno da ambivalência exposto por parte de uma das participantes:

“...Eu queria estudar, mas eu tive que esperar até o meu filho crescer um pouco porque não podia sobrecarregar tanto à minha mãe" (Participante 3)

“... os estudos de posgraduação e a publicação, falando a verdade, tiveram que esperar porque com crianças pequenas por elas serem tão dependentes de você, fazem com que seja muito difícil dedicar o tempo que isso precisa" (Participante 4)

Como pode-se observar no apontado pelas participantes, a tensão entre o cumprimento das metas acadêmicas e as demandas da família é uma constante e, geralmente, isso é assumido como uma condição natural da mulher. De acordo com Lagarde (2000) a vida acadêmica representa para a vida da mulher, em outras esferas e instituições sociais enquanto às marcas da desigualdade, a disparidade e a falta de liberdades que impactam o desempenho e limitam à sua realização pessoal mediante um conjunto de experiências práticas e as relações ambivalentes.

O equilíbrio é a receita que é suministrada não é somente impossível, se não que constitui um elemento mais de culpabilização e de transferência da responsabilidade política de reasignação dos pápeis e de poderes que as instituições sociais não asumem. $O$ seguinte fragmento mostra a encruzilhada que indica a ambivalência na qual se encontrou uma das participantes do estudo:

“...mas a Sônia significou algo muito importante para mim e é o fato de que eu ingressei no conselho universitário em abril do 85, tinha uns 38 anos, de que não não, foi no 86, tinha como 35 anos e eu disse puxa!, estou grávida e estou no conselho universitário e sou a primeira mulher que entra no conselho universitário, o que é que vou fazer meu Deus com a licença maternidade, nunca faltei ao conselho nem tendo obtido a licença. (Participante 1)

A alusão que faz a participante à divindade é mais do que um recurso retórico. Há três elementos que geram temor: a gravidez, a responsabilidade de ser integrante do conselho universitário, e o fato de ser a primeira mulher a ostentar essa posição. Esses três aspectos a colocam numa situação de ambivalência que resolve infringindo as normas legais estabelecidas (não cumprindo com a licença de maternidade).

Como parte das estratégias para atender a ambivalência é comum nas mulheres que recorram à família procurando um apoio que facilite seu desenvolvimento acadêmico. Isto parece contraditório, sendo que é justamente a família quem demanda atenções que representam para ela uma grande quantidade de energia e tempo. Um exemplo dessa situação pode-se observar no seguinte fragmento do relato de uma das participantes: 
"Quantas vezes a gente se deita à meia noite trabalhando e logo tem que se levantar às 5 h00 do dia seguinte para arrumar as crianças para escola e para depois ir trabalhar. No meu caso, em algumas coisas eu tive muito apoio, meu esposo me ajudava muito, mas muitas vezes não fez nada, ele não se levantou nenhuma vez para atender as crianças nas noites; isso sempre fiz eu sozinha. Porém, ele levava elas para a escola e às vezes dava de comer. Então em algumas coisas eles ajudam em outras não, mas mesmo ajudando, mesmo que ajude, tudo acaba caindo sobre a gente, as responsabilidades nos seguem" (Participante 3).

Como propõe Chavez (2009), a participação dos outro integrantes da família é concebida como uma ajuda ou colaboração que é dada à mulher, quem se supõe ser a responsável pelas tarefas vinculadas à educação das crianças e aos afazeres domésticos.

Essa condição está relacionada diretamente com uma das características assumidas na identidade feminina a qual deriva do conceito tradicional de mulher, esta é a noção de "mulher para outro", em contraposição com a "mulher para si própria"; tal como pode ser apreciado no verbatim oferecido a continuação:

"Para manter as minhas crianças tinha pluri-emprego, nesse momento tinha domingos nos quais eu, de pijamas, passava de trabalhando desde ás quatro da manhã até às cinco da tarde só tinha tempo para tomar banho e trocar de pijama e continuar trabalhando, não tinha outro jeito de fazêlo tinha que ser assim, cismada em terminar. Como trabalhava fazendo revisões filológicas lembro que tinha o mundo inteiro acima de mim exigindo a entrega dos trabalhos corrigidos e ali estava eu entre uma aglomeração de teses, outros documentos acadêmicos para corrigir, com a minha própria teses sem terminar e com todas as minhas crianças pedindo comida" (Participante 4).

O fragmento narrativo anterior ilustra bem o significado de "ser para o outro"; quer dizer, privilegiar as necessidades dos outros por encima das próprias. No caso analisado as necessidades vitais dela própria podem ser supridas só depois de que tenham sido satisfeitas as necessidades do resto dos integrantes da família.

O seguinte fragmento discursivo revela a realidade de muitas mulheres, para quem, o desenvolvimento de suas potencialidades foi adiado ou precedido pelas responsabilidades maternais ou conjugais:

"Você é brilhante ...sua grande limitação são seu parceiro e seus filhos. E eu respondi: provavelmente, mas essa sou eu, uma mulher não dividida, sou uma pessoa integral, sou filha, sou irmã, sou mãe, sou companheira, me apaixonei, não fui a mais afortunada, fazer o quê, tenho que devo vero como o sorteio." (Participante 1)

Outro elemento central nas identidades femininas é culpa, a qual funciona como um mecanismo altamente efetivo para que a mulher cumpra com todas as demandas requeridas, sejam as mesmas de proteção, de cuido e agora de produção (Lagarde, 1992). A situação não resolvida que implica ambivalência muitas vezes gera que as mulheres experimentem culpa por não cumprirem de forma total com as demandas do mundo familiar e do acadêmico. Convém relembrar que a culpa funciona para as mulheres, além de tudo como um mecanismos de controle social que permite reproduzir a ordem estabelecida.

Um exemplo de culpa pode ser percebido no seguinte fragmento:

"Mas sempre continuava. Eu me levantava às 2 ou 3 da manhã para continuar trabalhando e, é mais, às vezes estava com o meu parceiro ou fazendo algo e eu falava: [...] "Nossa, devo ir terminar tal coisa, tenho que fazer tal outra". A minha filha falou para mim: "Eu acho que no final papai foi 
embora porque ele percebeu que você não precisa dele e os homens precisam que se precise deles de verdade..." (Participante 1).

As condições descritas as condições descritas são enquadradas em um fenômeno maior que envolve a existência de mulheres: a naturalização. A ambivalência, tal como é proposta por Castro e Paredes, (2014) naturaliza-se, graças aos sistemas de adoctrinamento e ao habitus inscrito em suas mentes e nos seus corpos, de tal maneira que incorporam acriticamente as condições de opressão que realmente significa o cumprimento de dois e até de três jornadas de trabalho. Um caso extremo de ambivalência naturalizada pode ser observada na seguinte narração:

"Você veio grávida e hoje vem sem sua barrighinha, o que aconteceu, você está demonstrando que a licença maternidade não é necessária» Então eu respondi: Não senhor, a licença é válida para muitas mulheres, mas eu o que eu não quero é que nenhuma outra mulher desta universidade seja rejeitada porque poderia ficar grávida. Embora que eu ainda estava no período de quarentena, veja que assim vim...e assim também fiz quando estive no conselho. E estando nesse primeiro período do 86 ao 90 tive a minha segunda geração e nunca faltei ao CU..." (Participante 1)

Como pode ser deducido do verbatim, a professora movida pela vontade de cumprir com as demandas da academia, priva a sua própria pessoa dos direitos que legamente são inalienáveis; ess tipo de práticas extremas mostram exemplos da extralimitação à qual as mulheres podem chegar em casos de ambivalência.

Como se pode perceber, o envolvimento da professora no sistema meritocrático que supõe a ordem universitária, não só não considera as condições de ambivalência que condicionam às professoras universitárias, mas os exacerba, pois estabelece maiores exigências para ascender. Dali que tanto a ambivalência como a meritocracia se formem em condições de adversidade para as mulheres universitárias, tal como pode ser observado no seguinte fragmento do relato:

"É que a pessoa tem que começar a escrever um artigo depois de ter ido trabalhar e voltado em casa, ter preparado jantar, feitos deveres de casa com as crianças e até quando todos tenham ido se deitar, é ali quando você pode começar a escrever e logo disso se levantar ainda mais cedo para arrumar as crianças para a escola..." (Participante 3).

A ambivalência designa a interdependência das exigências contraditórias e que em qualquer das opções nas que a mulher se coloca termina sendo inadequada, pois deixa de atender a uma ou a outra. Conforme avança o desenvolvimento tecnológico, a ambivalência erigi-se com maior força, como uma condição características na existência da mulher: significa cumprir com jornadas de trabalho extenuantes que se estendem até as horas de descanso, férias e feriados e não são reconhecidos nem questionados por ninguém, nem mesmo pelas próprias mulheres. Um exemplo claro dessa situação pode ser visto na seguinte narrativa: "Eu consegui ser catedrática muito antes que outras colegas chegassem a sê-lo, porque en não tinha nem dias de folga, nem feriados, dediquei-me a escrever o tempo tudo quando não estava trabalhando na universidades e claro que isso é muito difícil quando você tem crianças pequenas emcima de você o dia todo" (Participante 3).

Resumindo, pode-se afirmar que a ambivalência é uma das situações que marcam mais profundamente a condição da mulher nas novas sociedades e que acaba sendo, per se, uma condição de opressão pelos efeitos que produz no nível psicológico e emocional, mas também em termos práticos no que se refere ao desempenho e a liberdade da mulher. 
Existem estudos nos quais é demostrado que o fato de que algumas professoras universitárias devam cumprir jornadas de trabalho duplas e ou triplíces que coloca elas em situação de risco de sofrer o sindrome de burnout em maior proporção se comparado com seus colegas do sexo masculino (Silva, Rodríguez \& Flores, 2009).

\section{Teto de cristal}

As barreiras invisíveis ás quais faz alusão este conceito de teto de cristal, podem ser classificadas em internas (intrínsecas à docente, que se associa acima de tudo à ambivalência, ou ao sentido de impotência e de automarginação) ou externas (próprias do sistema ou da organização universitária). A continuação, serão feitas alusões às barreiras externas que as participantes mencionaram a partir das situações relatadas.

No primeiro lugar, pode ser observado que algumas das barreiras que têm a ver com os obstáculos que são vividos durante o processo de inserção no mundo do trabalho universitário, tal como é evidenciado nos seguintes fragmentos:

"entrar na universidade não é fácil há muitos grêmios que dificultam a entrada e não é tanto pela capacidade senão é porque o chefe foi com a sua cara..." (Participante 3)

"Em algumas oportunidades existiam divergências porque se eu queria publicar eles diziam: "Não, essa não é a sua função. Sua função é organizar aqui que se façam as colheitas e tudo isso" (Participante 3).

"Quando comecei na universidade... era vista como se não fosse profissional...penso que as pessoas não me aceitavam porque era jovem e possívelmente também por ser mulher, e também por ser mulher fui vítima de certo assédio... Tinha a impressão de que talvez eles pensavam que eu era algo assim como uma caloura" (Participante 2).

Como pode-se apreciar no narrado pelas participantes, existem barreiras invisíveis (e algumas evidentes) que impossibilita o avanço na sua carreira acadêmica. Essas barreiras contrapõe-se às suas capacidades, e em muitos casos, as anulam. As narrações anteriores permitem perceber o contexto universitário como um lugar no qual são tecidas estruturas de funcionamento e pautas culturais que marginam às mulheres.

O ascenso acadêmico baseado no mérito, embora pareça um sistema justo para o pessoal acadêmico, na realidade não é, no caso das mulheres cujas condições diferentes aos dos colegas do sexo masculino e, por isso, não estão em uma posição de igualdade. Mas al[em disso, em múltiplas ocasiões experimentam atos discriminatórios imperceptíveis que às vezes impedem que haja um verdadeiro concurso igualitário pelas oportunidades (Cooper, 2014). Para as participantes do estudo algumas das experiências como docentes universitárias acarretaram obstáculos tecidos desde os céus profissionais do jeito que pode ser visto à continuação:

"Mas sim eu acredito que o que mais me doeu é que estando ali...é o machismo tão grande que existia particularmente na administração" (Participante 1)

"Quando cheguei nesta universidade tinha o número suficiente de publicações para poder ser catedrática... me deziam uma coisa e outra e assim foram me enrolando. Eu falei: Nem vou brigar, de todo jeito, eles vão decidir o que vão me reconhecer e o que não. Eu sinto que houve uma coisa alí 
tipo ciumes, e incomodidade. Suponho que deziam: Como é que ela chega assim e de vez vai ser catedrática?" (Participante 3).

"Para mim este foi um episódio muito triste, porque eu já tinha dedicado muito tempo à escritura deste livro. A encarregada da catédra dessa disciplina rejeitou o texto dizendo "Não vou usar esse livro" depois de que o mesmo já tinha sido acabado, revistado e contava com o aval das unidades didáticas, que assim era chamado antigamente esse lugar... Parecía mais uma coisa pessoal, eu não sei porquê" (Participante 2)

Pode-se observar, graças a estes depoimentos, que as expresões misóginas são manifestadas não somente pelos homens, mas também pelas mulheres da instituição universitária.

A masculinização da acadêmia é um fenômeno complexo, e para o caso das professoras que pretendem se abrir passo como cientistas e ter posições de mando, é ainda mais difícil que para aquelas que optam com ficar desempenhando cargos de docente auxiliar, quer dizer, com uma baixa categoria acadêmica, dentro da universidade. As narrações seguintes das participantes expressam a existência de um sistema universitário que subsiste de uma forma declaradamente paralela no discurso universitário, no qual a coação e o patriarcado ainda continuam presentes:

"A administração não aceitava que uma mulher que nem eu questionasse e raciosinasse. Às vezes o Luisi meu colega chegava e falava para mim assim: "Vai e diga mais de outra maneira, você tem razão, mas você está despindo a administração" (Participante 1).

"Escrevi um artigo que conmoveu esta...em consequencia terminei na rectoria, o artigo foi exposto em uma palestra que acho fazia refêrencia a educação a distância...que valorou o artigo apontpu que estava muito bem argumentado e fizeram a indicação de que eu tinha todo o direito de apresentá-lo... No lugar estavam os membros do Conselho Universitário, uma das integrantes do Conselho falour: "Tudo está fundamentado; não podemos fazer nada porque o eu ela está dizendo é verdadeiro!"'" (Participante 1).

"O reitor da universidade naquela época, ligo para mim e pediu que eu reparasse a criação do sindicato e eu respondi: "Sim, senhor, eu vou renunciar ao meu trabalho na instituição, não se preocupe com isso, somente precisso de um tempinho, em agosto eu lhe dou a minha demissão"; a que el respondeu: "Promete?", e eu, "Prometo, sim senhor! ..." (Participante 1).

Os fragmentos apresentados posuem o denominador comum de remitir a situações nas quais a liberdade de expressão das participantes viu-se limitada geralmente por alguma figura de autoridade da universidade que em todos os casos é masculina.

Sobre o assinalado destacam-se também outras manifestações discriminatória relacionadas mais com práticas de exclusão geradas por sistemas de apadrinhamento ou de élites dentro da Universidade, mediante os quais limita-se a participação real das mulheres no mundo acadêmico. Exemplo dessa práticas podem ser lidos nos seguintes fragmentos:

"Quando entrei... tive a impressão de que essas pessoas se sentiam serem os donos da universidade e me olhavam como se eu não fosse profissional. Eu senti tudo isso no olhar deles, eu sou uma pessoa muito perceptiva" (Participante 2).

"Nessa época na universidade era menor, quer dizer, nós tínhamos menos gente. Eu achei lá homens e mulheres que pensavam que a universidade era deles, tinham inclusive um ditado: "Quem vem chegando, vai ficando" (Participante 2). 
"Sinto que na universidade eu já tive algumas oportunidades, embora, como em tudo, sempre há pessoas que recebem mais ou menos dependendo do grau de proximidade com o grupo que detém o poder transitório na faculdade ou que está governando naquele momento na universidade “ (Participante 5).

Os relatos das participantes mostram uma clara forma de discriminação estabelecida através de sistemas compadrios ou elites que exercem uma força centrípeta para as professoras que ingressam na universidade, resultando em prolongados e violentos processos de inserção na vida profissional universitária auto-marginação, à qual estão estão adstritas muitas professoras cujos recursos internos não Ihes permitem trasncender as múltiplas expressões de agressão simbólica às que são submetidas por diversos grupos.

Outro tipo de barreiras ou discriminações experimentadas pelas participantes encontram-se no âmbito dos preconceitos de gênero, que além de ser violentos per se, alimentam práticas de exclusão e segregação, tal e como pode ser apreciado nos relatoas a continuação:

"Quando publiquei o meu primeiro livro, sendo apenas bacharel e estudante, entendi claramente que as mulheres deviam ser de baixo perfil, e que inclusive não deveriam parecer mulheres, coisa que é outro fato na ciência... as mulheres que emergiram no pensamento científico, que além de tudo não são poucas, são muitas, sempre tiveram que escoder a sua condição de mulher porque se não guardavam um perfil baixo, não iam chegar em lugar nenhum" (Participante 5)

"Formei-me em teatro e nunca coloquei um pé no cenário em uma obra profissional. Porque para ser atriz é necessário enfrentar preconceitos. Com o fato de considerar que se você não se dedicar tempo completo ao teatro não poderá ser atriz, o se você começar sendo adulta (e sendo mãe de várias crianças como foi meu caso) é tarde demais. Muitas vezes pessoas chegavam que falava assim para mim: "Você tem talento para o teórico, mas não tem talento para a parte da atuação". Mais, quem diz que não, se o talento também vai se obtendo mediante a prática!" (Participante 4)

A partir do que foi narrado percebe-se como os preconceitos de gênero funcionaram para as participantes como barreiras externas que obstaculizaram seu desenvolvimento acadêmico e profissional.

Além do sugerido, existem também formas mais explicitas de trato discriminatório associadas à condição de mulher, especificamente trata-se do assédio sexual por parte de homens colegas docentes, tal como pode-se apreciar nos seguintes fragmentos:

"Logo há outro problema que no é confrontado concernente à condição de mulher, e é que não faltam as propostas indecentes por parte dos professores, não podemos nem usar a palavra colega, porque ali as coisas devem se ter muito claras." (Participante 5)

"Isso é delicado... né? Um homem casado, que trabalhava no primeiro andar, começou a me convidar para almoçar. No início eu não achava nada de mais, mas sim...um dia ele resolveu passar pela minha casa... nisso eu aida morava com a minh mãe... Em fim... eu tive que confrontar ele" (Participante 2)

"... ele me fez a proposta de ir por um drinque. Como se tratave só de beber alguma coisa eu aceitei. Mas enquanto a gente bebia ele me pediu que fóssemos para um outor lugar. E ele falava assim: "Vamos para um lugar onde eu possa te paparicar" e não sei mas o que. Eu não entendi no instante e então eu falei: "Me diga uma coisa, o senhor está pensando no quê... num motel ou algo assim?" E ele respondeu: "Sim..." E aí eu respondi: "Não... não, não! Fique sabendo que para isso eu preciso amar à pessoa e as coisas não são assim não" (Participante 2). 
Assim como as expressões do androcentrismo apresentadas violentam diretamente às mulheres, é possível também encontrar no contexto estudado, outras formas de misoginia que operam como barreiras e podem se ilustradas com a narração seguinte:

"A rejeição às mulheres é terrível, não só porque a maioria são homens, se não porque também existem uma série de preconceitos que mantêm aos estudiosos da filosofia continuam usando o Aristóteles ou o Tomás de Aquino como referência, personagens para quem as mulheres não são capazes de pensar, e essa crença tem-se extendido para outras áreas da ciência, e tem marcado a psicologia, a educação, e outros âmbitos do pensamento" (Participante 5).

Perante a cultura androcêntrica, estas mulheres desenvolvem estratégias que permitem que elas avancem academicamente sem contrariar de frente aos colegas do sexo masculino, inclusive, defender-se em situações associadas à misoginia que é disfarçada no claustro universitário no qual elas estão adstritas, tal como pode observar-se no seguinte verbatim:

"Muitas mulheres optam pela camuflagem, quer dizer, o fato de não destacar muito porque destacar muito, acontece algo, e ela começa a sentir uma atitude no ambiente por parte dos colegas e também por parte das colegas mulheres." (Participante 5).

A camuflagem ou invisibilidade é uma estratégia que tem sido utilizada de forma muito eficaz por algumas professoras universitárias, em resposta à dominação simbólica, para avançar nas carreiras profissionais e crescer academicamente, mesmo em condições de sigilo.

\section{DISCUSÃO}

A ambivalência e o teto de cristal que caraterizam a condição das professoras universitárias são elementos amplamente estudados (Flores, Soto \& Espejel, 2013). Apesar dos esforços feitos pelas teóricas da disciplina (De Garay \& Del Valle-Díaz-Muñoz, 2012; Buquet, 2014), essa situação continua sendo uma limitação para as professoras universitárias no seu desenvolvimento acadêmico. Estes fenômenos expressam, à sua vez, condições estruturais de desigualdade, invisibilização e violência contra a mulher.

Os casos analisados na pesquisa aproximam-se do apresentado pela literatura especializada sobre as maiores dificuldades vivenciadas pelas professoras universitárias para avançar nas carreiras acadêmicas. Devido as condições estruturais adversas que bloqueam o avanço das docentes, especialmente, em aquelas situações derivadas da falta de um apoio verdadeiro por parte da família, a carência de esquemas institucionais que forneçam suporte; a maternidade, a educação dos filhos e as responsabilidades com a família nuclear e com a família ampliada (Moncayo \& Zuluaga, 2014). Somado a essa enumeração de situações externas, estão também as barreiras internas associadas à ideologia da mística da feminilidade (como é o caso da exaltação da capacidade de dar e da experimentação da culpa) que bloqueiam o avanço das mulheres na carreira acadêmica (Friedan, 1963, Tomàs, Durán, Guillamón \& Lavié, 2008). O ambiente universitário está permeado pela desigualdade e a disparidade que ainda persiste nas sociedades pós-modernas. As condições de desigualdade entre homens e mulheres no mundo acadêmico são encriptadas pela neutralidade que historicamente tem-se atribuído ao desenvolvimento científico e acadêmico, tal e como o sugerido pelas autoridades no tema (Moncayo \& Zuluaga, 2014).

O sistema meritocrático que rege a carreira profissional na universidade não reconhece que as professoras pela sua condição de mulheres, cumprem com papéis socialmente atribuídos que as coloca em uma clara desvantagem com respeito aos seus colegas do sexo masculino. O cumprimento dos mandados 
sociais implica que muitas professoras devam adiar seu desenvolvimento acadêmico e seu ascenso na carreira docente até seus filhos crescerem e, nesse momento, perto do ocaso da vida, iniciar o se ascenso na carreira profissional, isso unido ao esgotamento acumulado pelos anos de ter jornadas de trabalho duplas e tríplice.

Apesar de que as professoras incluídas no estudo não consideram a ambivalência um assunto que mereça ser analisado, as condições nas quais se dá o desenvolvimento acadêmico das mesmas apresenta marcas claras de sobre-exploração, de ambivalência e de diferentes expressões de teto de cristal. Porém, essas condições parecem ser legitimadas e naturalizadas. Ou seja, a ambivalência e os tetos de cristal aparecem como aspectos com os que deveria lidar cada mulher que resolve incursionar no mundo acadêmico. Isto poderia estar estreitamente relacionado com os processos de ideologização que as mulheres têm experimentado no decorrer da história e ao longo da sua existência nas sociedades sinalizadas pelo patriarcado e o androcentrismo (Lozano, Iglesias \& Martínez, 2014).

\section{CONCLUSÕES}

No desenvolvimento profissional docente das participantes, a ambivalência está presente de forma constante que funciona como uma das barreiras internas com as quais as professoras devem enfrentar-se para avançar nas suas carreiras acadêmicas, bem como no regime de ascenso docente que caracteriza às instituições universitárias. Essa ambivalência implica condições de sobre-exploração para as mulheres que se propõe altas posições, tanto dentro do regime docente como nas estruturas de tomadas de decisões nas universidades. O dito anteriormente, se deve a que estas mulheres devem cumprir jornadas de trabalho duplas ou tríplices.

As barreiras externas, ou tetos de cristal, para as docentes universitárias materializam-se de formas diferentes, assumindo expressões de exclusão-marginação, invisibilização, discriminação por preconceitos de gênero e assédio sexual.

A ambivalência e os tetos de cristal com frequência são naturalizados na cotidianidade da vida universitária. Essa naturalização corresponde a uma legitimação dos sistemas meritocráticos que prevalecem na universidade, nos quais não se reconhecem as diferenças de gênero do professorado, pois, estão sujeitos a um raciocínio androcêntrico e patriarcal.

\section{REFERÊNCIAS}

Bolívar, A.; Domingo, J. \& Fernández, M. (2001). La investigación biográfico-narrativa en educación. Madrid: La Muralla.

Buquet, A. (2014). Género y educación superior: una mirada desde América Latina. Ponencia presentada en el Seminario Internacional Calidad de la educación superior y género en América Latina. 18 al 20 de junio de 2014, Quito, Ecuador. Organizado por FLACSO-Sede Ecuador.

Castro, C. y Paredes, M. C. (2014). 'Habitus' cultural y violencia simbólica en las relaciones de género en la academia. Caso de estudio: Universidad de Cuenca-Ecuador. Ponencia presentada en el Seminario Internacional Calidad de la educación superior y género en América Latina. 18 al 20 de junio de 2014, Quito, Ecuador. Organizado por FLACSO-Sede Ecuador.

Chávez, R. (2009). La transversalidad del género entre la profesión y la familia. Una experiencia vivida. en Género y trabajo en las universidades. Coordinadoras María Antonia Chávez Gutiérrez, María Rita Chávez Gutiérrez, Ericka Ramírez Diez, María Elena Cruz Muñoz, Gabriela Karina Cervantes Fuentes. 
Clarke, M. (2011). Advancing women's careers through leadership development programs. Employee Relations, 33, 498-515. doi:10.1108/01425451111153871

Cook, A., \& Glass, C. (2014). Women and top leadership positions: Towards an institutionalanalysis. Gender, Work \& Organization, 21, 91-103. doi:10.1111/gwao.12018

Cooper, J. (2014). ¿Por qué la meritocracia traiciona a las mujeres académicas en las instituciones de educación superior? Análisis y propuestas. Ponencia presentada en el Seminario Internacional Calidad de la educación superior y género en América Latina. 18 al 20 de junio de 2014, Quito, Ecuador. Organizado por FLACSO-Sede Ecuador.

De Garay, A. \& del Valle-Díaz-Muñoz, G. (2012). Una mirada a la presencia de las mujeres en la educación superior en México. Revista Iberoamericana de Educación Superior, 6(3). 3-30.

Eagly, A. H., \& Karau, S. J. (2002). Role congruity theory of prejudice toward female leaders. Psychological Review, 109, 573-598. doi:10.1037/0033-295X.109.3.573

Flecha, C. (2003). La mirada de las mujeres al mundo académico. Revista argentina de sociología. 1(1). 27-43.

Flores, A. Soto, S. \& Espejel, A. (2013). Entre "la casa y la ciencia": mujeres científicas en Tlaxcala, México. Revista Perspectivas sociales/social Perspectives. 15 (2). 69-102.

Friedan, B. (1963). The feminine mystique. New York: Norton.

Fuchs, C., Sauté, R. Oglensky, B. \& Gever, M. (1995). Glass Ceilings and Open Doors: Women's Advancement in theLegal Profession, 64 Fordham L. Rev. 291. Recuperado de: http://ir.lawnet.fordham.edu/flr/ vol64/iss $2 / 2$

Hoyt, C. L. (2010). Women, men, and leadership: Exploring the gender gap at the top. Social \& Personality Psychology Compass, 4, 484-498. doi:10.1111/j.1751-9004.2010.00274.x

Jackson, J. F., \& O'Callaghan, E. M. (2009). What do we know about glass ceiling effects?A taxonomy and critical review to inform higher education research. Research in Higher Education, 50, 460-482. doi:10.1007/s11162-009-9128-9

Martínez, S. (2012). Ser o no ser: tensión entre familia, subjetividad femenina y trabajo académico en Chile: un análisis desde la psicología feminista. La ventana. Revista de estudios de género. 4 (35). 133163. Recuperado de: http://www.scielo.org.mx/pdf/laven/v4n35/v4n35a6.pdf

Moncayo, B. \& Zuluaga, D. (2014). Liderazgo y género: barreras de mujeres directivas en la academia. Pensamiento y gestión, 39, pp. 142-176.

Lagarde, M. (1992). Género e Identidades. Metodología de Trabajo con Mujeres. Ecuador: UNDETEC y UNICEF.

Lagarde, M. (2000). Autoestima y Género: Claves feministas para la autoestima de las mujeres. Cuadernos inacabados. 39. Recuperado de https://mega. nz/\#!MrJ1HT6I!wTu6r4V-jW5xfCVwPBrcS4xJNdLVxI4oWXHAz3n7Awo

Lozano, I. Iglesias, M. \& Martínez, M.A. (2014). Las oportunidades de las académicas en el desarrollo profesional docente universitario: un estudio cualitativo. Educación XXI, 17(1). 159-182.

Palomar, C. (2009). Maternidad y mundo académico. Alteridades. 19(38), 55-73.

Silva, B., Rodríguez, A. \& Flores, R. (2009). Desgaste profesional y aspectos psicosociales del trabajo académico en la población femenina. en Género y trabajo en las universidades. Coordinadoras María Antonia Chávez Gutiérrez, María Rita Chávez Gutiérrez, Ericka Ramírez Diez, María Elena Cruz Muñoz, Gabriela Karina Cervantes Fuentes.

Tomàs, M., Durán, M., Guillamón, C. \& Lavié, J. M. (2008). Profesoras universitaria y cargos de gestión. Recuperado de https://publicaciones.unirioja.es/ojs-2.4.2/index.php/contextos/article/view/598 
Tomàs, M., Castro, D. \& Durán, M. (2011). Aproximación a un modelo de análisis de la visibilidad en la Universidad desde la perspectiva de género. Bordón 64(1), 141-155.

Tomàs, M., Ion, G. \& Bernabeu, M. D. (2013). Ser o no ser visible en la universidad. Un estudio sobre las profesoras de Pedagogía Social. Revista Interuniversitaria. (21), 189-211.

Valcárcel, A. (2012). La política de las mujeres. 5ta edición. Madrid: ediciones cátedra.

Vicente, G. (2003). Mujeres en el mundo académico español. Thémata. Revista de filosofía. 31.173-185. 